\title{
ULTRASTRUCTURAL DEMONSTRATION
}

OF CYTOCHROME OXIDASE AC'TIVITY

\author{
BY THE NADI REACTION
}

WITH OSMIOPHILIC REAGENTS

\author{
ARNOLD M. SELIGMAN, ROBERT E. PLAPINGER, HANNAH L. \\ WASSERKRUG, CHANDICHARAN DEB, and JACOB S. HANKER
}

From the Department of Surgery, Sinai Hospital of Baltimore 21215, and The Johns Hopkins University School of Medicine, Baltimore, Maryland

\begin{abstract}
A new method for the subcellular and cytochemical demonstration of cytochrome oxidase has been developed with the introduction of $N$-benzyl-p-phenylenediamine (BPDA) and the discovery that indoanilines are osmiophilic. These indoanilines produced upon oxidation of BPDA in the presence of naphthols are highly colored compounds that yield electronopaque coordination polymers of osmium (osmium black) that are amorphous, insoluble in water, and in organic solvents. The best methods for preparing rat tissue were in decreasing order: fixation in formaldehyde solution, fresh tissue slices, and frozen sections of fresh or fixed tissue. Ultrathin sections were counterstained by bridging with the thiocarbohydrazide-osmium tetroxide ( $\mathrm{T}-\mathrm{O}$ ) procedure for enhancing underlying membranous structures. Cytochrome oxidase activity was noted primarily in mitochondria and occasionally in sarcotubules of heart, in mitochondria and occasionally in infoldings of the plasma membrane of renal tubular cells, and in mitochondria and, to a great extent, in endoplasmic reticulum of hepatic cells. Cytochrome oxidase activity produced deposits in droplet form, whereas dehydrogenase activity resulted in uniform staining of mitochondrial cristae, as recently demonstrated with an osmiophilic tetrazolium salt. Even more recently we have succeeded in demonstrating cytochrome oxidase activity in nondroplet staining on mitochondrial cristae with an osmiophilic benzidine-type reagent that apparently polymerizes upon oxidation (to be published later).
\end{abstract}

In order to develop new cytochemical methods for electron microscopy that would supplement the metal salt methods for hydrolytic enzymes and possibly avoid some of their pitfalls, we have introduced new histochemical principles $(5,7,8$, 20). One principle is based upon the use of organic reactions that yield insoluble pigments which possess an osmiophilic group. The immediate conversion of the reaction product into osmium black on exposure to osmium tetroxide helps to diminish the artifacts due to possible diffusion of the organic reaction product or due to special affinities of reaction product such as lipid solubility. The osmium black so produced is a coordination polymer of osmium (6) and has ideal properties for both light and electron microscopy.

In order to do the same for cytochrome oxidase, we could have introduced the osmiophilic group into either of the two components of the Nadi reaction. In our earlier experiments $(7,8,20)$, 
an osmiophilic thiol function was incorporated into the substituent groups of a 2-substituted and 5substituted 1-naphthol, and both phenylenediamine derivatives developed for cytochrome oxidase histochemistry $(2,14)$ were used; i.e., 4amino-1- $N, N$-dimethyl napthylamine (I) or 4aminodiphenylamine (II). The two substituted naphthols used in our early experiments $(7,8$, 20) were 1-hydroxy-4'-mercapto-2-naphthanilide (III) and 1-hydroxy-2'-mercapto-5-naphthanilide (IV). Although these naphthols did not react with the original Nadi reagent, $N, N$-dimethyl- $p$ phenylenediamine, they did react to some extent with the diamines (I and II). However, both diamines (I and II) were found equally capable of reacting with themselves in the absence of naphthols, and the pigments obtained had a light brown and purplish color similar to that given in the presence of the substituted naphthols (III and IV) (16). This made it difficult to determine to what extent reaction had occurred with the substituted naphthols. In order to increase the reactivity of these substituted naphthols in the Nadi reaction, we introduced two new naphthols in which a smaller substituent function was introduced into ring $\mathbf{B}$ of 1-naphthol. These were the 5-substituted (V) and 6-substituted (VI) methylthioureido $\left(\mathrm{CH}_{3} \mathrm{NHCSNH}-\right)$ 1-naphthols. The reactivity of the latter naphthols was presumably somewhat greater, although the two diamines (I and II) reacted with themselves as readily as with these naphthols to give similar light brown and purplish products, respectively. In order to further decrease the extent of the reaction of amine with itself, we introduced a new phenylenediamine (16). This amine is $N$-benzyl-pphenylenediamine (BPDA) (Fig. 1). It gives bright green or blue indoanilines in the Nadi reaction with the substituted 1-naphthols (V, VI) as well as with l-naphthol, and an almost imperceptibly pale brownish-yellow color when two molecules of BPDA react together to form an indamine or when substituted naphthols III and IV are present. Because of the striking color difference, it was easy to show that the reaction of BPDA in the presence of 1-naphthol (Fig. 1) or the substituted naphthols ( $V$ and $V I$ ) was essentially completed with them, whereas there was little reaction with the substituted naphthols III and IV. We also discovered that the quinonoid products (indoanilines and indamines) resulting from any of these amines reacting with 1-naphthol or
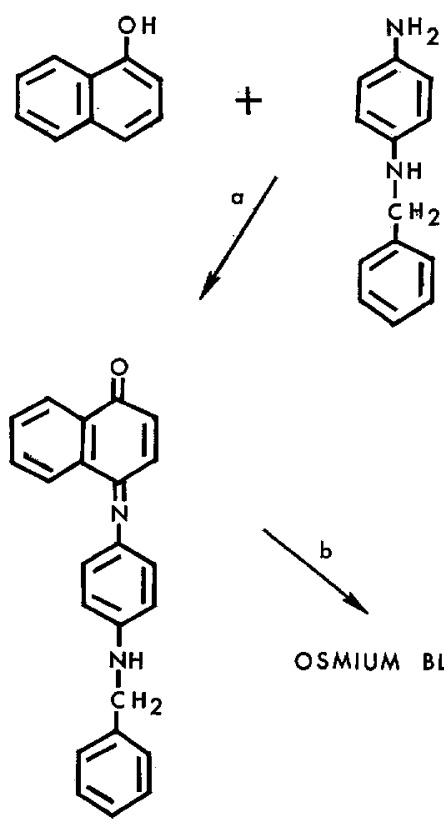

OSMIUM BLACK

Figure 1 Reaction of $N$-benzyl- $p$-phenylenediamine (BPDA) with 1-naphthol to form an indoaniline derivative which is converted to an osmium black, a coordination polymer (6), a), cytochrome oxidase and cytochrome $c ; b$, osmium tetroxide.

with itself are osmiophilic (16). Therefore, it was clear that a second osmiophilic group had been introduced into the reaction product by the use of substituted naphthols (III, IV, V, VI). Whether a second osmiophilic group was important or not had to be determined by electron microscopy.

The results with light microscopy were quite similar with all of these reagents. The purplishcolored pigments (with amines I and II) or bright blue pigments (with BPDA), which are all extractable with organic solvents, were converted after exposure to osmium tetroxide to osmium black, a coordination polymer of osmium (6) which is not extractable with organic solvents. Cytochrome oxidase activity in heart muscle was localized in the form of small numerous black deposits that strongly suggested localization in mitochondria, whereas in liver and kidney the deposits could not be correlated with the distribution of mitochondria (Figs. 1 and 2 of reference 20). In order to study this apparent discrepancy more closely, we examined these two organs of the rat in the electron microscope with our newly developed reagents and techniques. Preliminary results 
with amines (I and II) and substituted naphthols (III and IV) have been published $(7,8,20)$. The syntheses of the substituted osmiophilic naphthols (III, IV, V, VI) are given elsewhere (16), and the preparation of $N$-benzyl- $p$-phenylenediamine dihydrochloride (BPDA) is included here.

We tested various procedures for preparing the tissue in earlier studies $(7,8,20)$ in order to find the best method for preserving the ultrastructure. The best methods were in decreasing order: fixation in methanol-free formaldehyde (prepared from paraformaldehyde) (15), fresh tissue slices, and thick frozen sections of fresh or fixed tissue. Tissues fixed in formaldehyde for 30 min were stained in small blocks, and tissues fixed for $1 \mathrm{hr}$ were cut in $30-\mu$ sections with a Smith-Farquhar chopper (24). Hydroxyadipaldehyde fixation as recommended by Sabatini et al. (19) was also tried, but the results were less satisfactory than when brief formaldehydefixed or fresh heart was used $(7,8,20)$. We stained ultrathin sections, embedded in Maraglas (4), with uranium and lead to enhance contrast of ultrastructure according to methods of Reynolds (17) and Karnovsky (9) in the earlier studies $(6,7,20)$. However, following development in this laboratory of the OTO method (23) for enhancing contrast of membranous structures and lipid droplets, this method was applied to the ultrathin sections which had been stained for cytochrome oxidase. All ultrathin Araldite sections from which the plates for this paper were made were first exposed to thiocarbohydrazide ( $\mathrm{TCH}$ ) followed by exposure to osmium tetroxide (T-O procedure). Unstained sections were also studied. This procedure has also been used to reveal underlying ultrastructure for other enzymatic methods $(5,21,22)$.

\section{METHOD}

Preparation of N-Benzyl-p-Phenylenediamine Dihydrochloride $(B P D A)^{1}$

$N$-Benzyl-p-phenylenediamine dihydrochloride was prepared by catalytic reduction of $N$-benzyl-4-nitro-

\footnotetext{
${ }^{1} \mathrm{~N}$-Benzyl-p-phenylenediamine dihydrochloride (BDPA) and osmium tetroxide may be obtained from Polysciences, Inc., Rydal, Pennsylvania. Ampoules containing $1 \mathrm{~g}$ of osmium tetroxide were opened in a hood, and the osmium tetroxide was placed on a plastic tray, divided into eight equal portions and each 1/8-g portion was brushed into a 1/2-oz French square bottle with a small teflon brush, capped securely with a teflon liner, and kept at $-20^{\circ} \mathrm{C}$ until necded.
}

aniline. The latter was synthesized via a nucleophilic displacement reaction of benzylamine on 4-nitrofluorobenzene by a modification of the procedure of R. Lantz and P. Obellianne (11).

N-BENZYL-4-NITROANILINE ${ }^{2}: 4$ - Nitrofluorobenzene $28.2 \mathrm{~g}(0.20 \mathrm{~mole})$ and benzylamine $42.8 \mathrm{~g}(0.40 \mathrm{~mole})$ were placed in a two-necked flask containing $250 \mathrm{ml}$ of dry dimethylacetamide and stirred mechanically at $100^{\circ} \mathrm{C}$ for $20 \mathrm{hr}$. On cooling to room temperature, the solid which settled ( $8.5 \mathrm{~g})$ was filtered (benzylamine hydrofluoride). It was insoluble in ethanol and ether and soluble in water. Water $(25 \mathrm{cc})$ was added to the $N, N$-dimethylacetamide solution of the product which was then poured with stirring into 2 liters of ice water. The yellow product, $N$-benzyl-4-nitroaniline, was filtered, washed with cold water, and dried in a vacuum desiccator. Yield $46 \mathrm{~g}, 100 \%, \mathrm{mp} 142-144^{\circ} \mathrm{C}$. Recrystallization was effected from ethanol-water or acetone-water. The recrystallized material melted at $149-150^{\circ} \mathrm{C}$.

Anal. Calcd. for $\mathrm{C}_{13} \mathrm{H}_{12} \mathrm{~N}_{2} \mathrm{O}_{2}: \mathrm{C}, 68.41, \mathrm{H}, 5.30$, N, 12.27 .

Found: G, 68.15, H, 5.08, N, 11.98 .

N-BENZYL-P-PHENYLENEDIAMINE DIHYDROCHLORIDE: $N$-Benzyl-4-nitroaniline $10 \mathrm{~g}$ (0.044, mole) was dissolved in $150 \mathrm{cc}$ of tetrahydrofuran and $100 \mathrm{cc}$ of absolute methanol was then added. This solution was hydrogenated over platinum oxide $(440 \mathrm{mg}$ ) at $60 \mathrm{lb}$ per sq in in a Paar Hydrogenator.

The hydrogenator was allowed to shake for only an additional 2 min after 2.9 moles of hydrogen per mole of $N$-benzyl-4-nitroaniline had been taken up to prevent hydrogenolysis of the benzyl group. Pressure drop theoretical $=10.8 \mathrm{lb}$; pressure drop actual $=10.5 \mathrm{lb}$.

The catalyst was filtered rapidly over Celite (Johns Manville), and the product precipitated when $60 \mathrm{cc}$ of methanol containing $7.5 \mathrm{~g}$ of dry hydrogen chloride was added to the filtered solution. We added ether to insure complete precipitation of the product, and the dihydrochloride was filtered, washed with ether, and dried in a vacuum desiccator. Yield $102 \mathrm{~g}, 85 \%$. $N$-Benzyl-p-phenylenediamine

${ }^{2}$ Utilizing the exact procedure of R. Lantz and P. Obellianne (11) (refluxing for $3 \mathrm{hr} 2.8 \mathrm{~g}$ of 4-nitrofluorobenzene with $2.2 \mathrm{~g}$ of benzylamine in $20 \mathrm{cc}$ of water containing $1.8 \mathrm{~g}$ of $\mathrm{Na}_{2} \mathrm{CO}_{3}$ followed by cooling), we obtained $3.97 \mathrm{~g}$ of $\mathrm{N}$-benzyl-4-nitroaniline $(87 \%)$ melting at $143^{\circ} \mathrm{C}$. J. H. Billman and C. Diesing (1) reported a melting point of $146.5-147^{\circ} \mathrm{C}$ for this compound prepared in $90 \%$ yield by sodium borohydride reduction of the Schiff base derived from benzaldehyde and the $p$-nitroaniline. R. Meldola and E. H. R. Salmon (12) prepared this compound from 4-nitro-aniline and benzyl chloride, but did not report the yield. 
dihydrochloride starts to sinter at $173^{\circ} \mathrm{C}$, turning red at the outer edges of the crystals when viewed under a Fisher-Johns melting point apparatus. The decomposition proceeds from the edges toward the center of the crystal as the temperature rises, decomposition being complete at $195^{\circ} \mathrm{C}$. Meldola and Coste (13) prepared this compound by reduction of $N$-benzyl-4-nitroaniline with tin and hydrochloric acid. They reported a melting point of $30^{\circ} \mathrm{C}$ for the free base, but gave no melting point for the dihydrochloride, which gave a correct analysis for nitrogen and chlorine.

The white crystalline dihydrochloride may be stored at room temperature in an amber bottle without discoloration for at least a year, indicating much greater stability than diamines I and II, previously used in the demonstration of cytochrome oxidase $(2,14)$.

Anal. Calcd. for $\mathrm{C}_{13} \mathrm{H}_{16} \mathrm{~N}_{2} \mathrm{Cl}_{2}$ : $\mathrm{C}, 57.57, \mathrm{H}$, $5.94, \mathrm{~N}, 10.33$.

Found: C, 57.80, H, 5.91, N, 10.54.

\section{Preparation of Tissue}

Heart, liver, and kidney tissues were obtained from adult Wistar rats sacrificed by a blow to the head. Both chest and abdominal cavities were immediately opened and portions of the heart, liver, and kidney were removed and cut with a razor blade into blocks $\left(1 \mathrm{~mm}^{3}\right.$ and $2 \times 3 \times 5 \mathrm{~mm}$ ) Small blocks were used fresh, and both small and large blocks were fixed in cold $4 \%$ formaldehyde, prepared by depolymerization of paraformaldehyde with alkali, and neutralized to $\mathrm{pH} 7.4$ (15). The small fresh blocks of rat heart and small blocks of rat heart, liver, and kidney fixed in formaldehyde for $30 \mathrm{~min}$ were stained for cytochrome oxidase in 7.5 $\mathrm{ml}$ of staining medium. The larger blocks of heart, liver, and kidney were fixed for $1 \mathrm{hr}$, cut into $30-\mu$ sections with a Smith-Farquhar chopper (24), and these sections were stained in similar manner. All fixed tissues were washed for $15 \mathrm{~min}$ in $0.22 \mathrm{M}$ buffered sucrose $0.1 \mathrm{~m}$ with respect to phosphate, at $\mathrm{pH}$ 7.4. Incubation in the medium was performed at room temperature for $20 \mathrm{~min}$.

\section{Incubation Medium}

Stock solution of 1-naphthol or substituted naphthol $(\mathrm{V}$ or VI) $(1 \mathrm{mg} / \mathrm{ml}) \ldots \ldots 2 \mathrm{ml}$ $N$-benzyl- $p$-phenylenediamine dihydrochloride $(\mathrm{BDPA})^{\mathrm{I}}(2 \mathrm{mg} / \mathrm{ml}) \ldots \ldots \ldots .2 \mathrm{ml}$

0.1 M sodium phosphate buffer ( $\mathrm{pH} 7.4$ ) and $0.44 \mathrm{~m}$ in sucrose ............ $3 \mathrm{ml}$ catalase $^{3}(0.03 \mathrm{mg} / \mathrm{ml}) \ldots \ldots \ldots \ldots \ldots . .5 \mathrm{ml}$ cytochrome $c^{3} \ldots \ldots \ldots \ldots \ldots \ldots \ldots 7 \mathrm{mg}$

${ }^{3}$ Purchased from Sigma Chemical Co., St. Louis, Mo.
The solution of BPDA was made immediately before use. The stock solutions of 1-naphthol and of substituted naphthols (V and VI) were prepared by dissolving $10 \mathrm{mg}$ of each in $0.1 \mathrm{ml}$ ethanol and diethyleneglycol dimethylether, respectively, followed by the addition of $10 \mathrm{ml}$ of water, and filtration. These stock solutions were prepared daily, although this may not be necessary. At the end of the incubation period, the blocks of tissue were washed three times for 5 min each in $0.22 \mathrm{M}$ buffered sucrose, $0.1 \mathrm{M}$ with respect to phosphate $(\mathrm{pH} 7.4)$ at room temperature. The blocks were exposed to osmium tetroxide vapor for $40 \mathrm{~min}$. They were supported on a stainless steel screen supported in a 1/2-oz French square vial, screw-capped with a teflon liner, and containing $1 / 8 \mathrm{~g}$ osmium tetroxide ${ }^{1}$ and a few drops of water to prevent excessive drying of the tissue. The vial was placed on its flat side in contact with a sand bath at $55^{\circ} \mathrm{C}$. An alternate method of osmication was by immersion of blocks or sections in $1 \%$ aqueous, unbuffered osmium tetroxide at $50^{\circ} \mathrm{C}$ for $1 \mathrm{hr}$. Osmication of the quinonoid group proceeded rapidly, whereas osmication of the methylthioureido group required $40 \mathrm{~min}$ of osmium tetroxide vapor. Although osmication of the quinonoid group could be performed by placing the blocks or sections in $1 \%$ unbuffered osmium tetroxide solution at $50^{\circ} \mathrm{C}$ for 1 $\mathrm{hr}$, the results were a little better, though more costly, with osmium tetroxide vapor. The blocks were then dehydrated and embedded in Araldite (18). Ultrathin sections were cut on either a Porter-Blum microtome (MT2) or an LKB Ultratome equipped with a glass knife. Care was taken to insure the inclusion of tissue from the reactive surfaces of the blocks. Some sections, mounted on copper grids, were inspected without staining. Other sections were mounted on gold or nickel grids, and were treated with the T-O procedure (23). For this, they were exposed to a $1 \%$ aqueous solution of thiocarbohydrazide at $50^{\circ} \mathrm{C}$ for $1 \mathrm{hr}$. The sections were then washed a few times in warm water and osmicated for $1 \mathrm{hr}$ in a LKB grid holder cut to fit into a 1/2-oz French square vial, screw-capped with a teflon liner, and containing $1 / 8 \mathrm{~g}$ osmium tetroxide. ${ }^{1}$ The vial was placed on its flat side in a sand bath at $55^{\circ} \mathrm{C}$. To conserve osmium tetroxide, we cooled the top side of the bottle with an ice-containing aluminum foil dish before opening the bottle to remove the grids. An alternate method of osmication was by immersion of grids in $2 \%$ aqueous, unbuffered osmium tetroxide at $50^{\circ} \mathrm{C}$ for $1 \mathrm{hr}$. The excess osmium tetroxide on the grids was allowed to evaporate in a ventilated hood, and the sections were then studied with an RCA $\mathrm{EMU}_{3}$ (model H) electron microscope at $50 \mathrm{kv}$ or $100 \mathrm{kv}$ with a $30-\mu$ aperture.

Controls consisted of omitting the BPDA or the 


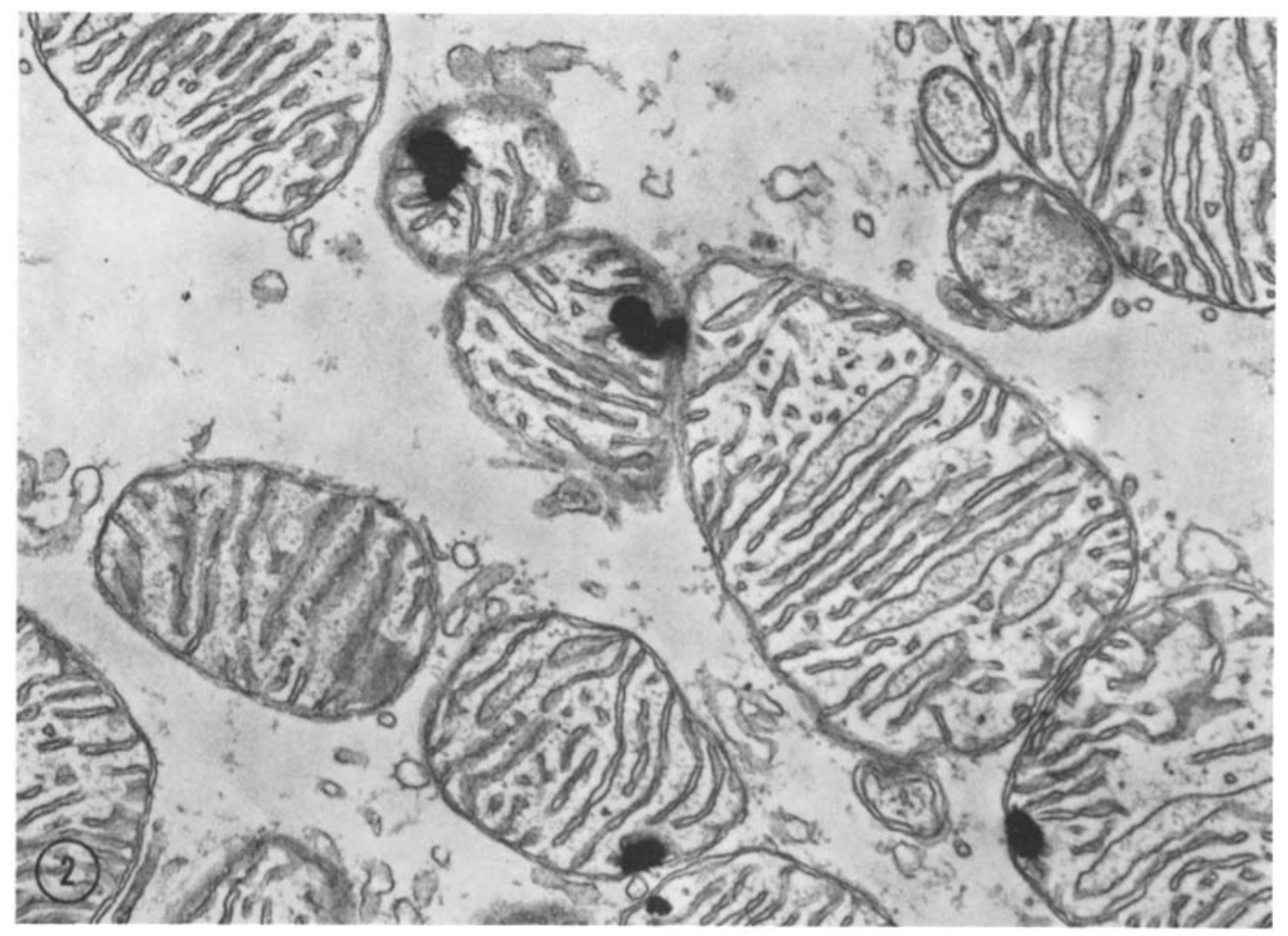

Figure 2 Fresh rat heart. Cytochrome oxidase in opaque droplets; with reagents $N$-benzyl-p-phenylenediamine (BPDA) and 1-naphthol followed by osmication. Counterstained on a gold grid with the T-O procedure (23). Note location of deposits near inner limiting mitochondrial membranes. $\times 19,000$.

naphthol from the incubation medium. Intramitochondrial deposits, other than normally occurring occasional dense granules, were not seen in the controls from which the BPDA was omitted. When the naphthol alone was omitted, cytochrome oxidase was demonstrated by the reaction of amine with itself. When 1-naphthol or naphthols $V$ and VI alone were used, the deposits were not seen.

Control experiments were also performed with the cytochrome oxidase inhibitor, $0.01 \mathrm{~m}$ potassium cyanide. Tissue blocks fixed in formaldehyde for 30 min, as well as thin frozen sections prepared from these blocks, were preincubated for $30 \mathrm{~min}$ in 0.01 M potassium cyanide solution, 0.22 м with respect to sucrose. Potassium cyanide $(0.01 \mathrm{M})$ was also included in the incubation medium. Incubation was for $60 \mathrm{~min}$. Although inspection of frozen sections showed complete inhibition, electron microscopic study of Araldite-embedded, ultrathin sections was made and also showed complete inhibition.

The omission of cytochrome $c$ from the medium resulted in a little less reaction product as noted with frozen sections of formaldehyde-fixed heart, kidney, and liver. With ultrathin sections, no significant differences were noted in the electron microscope. It is doubtful whether significant amounts of added cytochrome $c$ can penetrate very far into tissue blocks, so that the reaction in blocks or thick sections depends upon endogenous cytochrome $c$. This is probably also true for catalase. The $\mathrm{T}-\mathrm{O}$ procedure (23) on all sections, including controls, enhanced contrast of mitochondrial cristae, dense granules, and fat droplets as well as the myofibrils and sarcotubules. Sections both treated or untreated with the T-O procedure were studied. Mitochondrial swelling was seen in incubated tissues, especially fresh tissue, as well as in incubated controls as compared to tissue blocks immediately fixed in osmium tetroxide.

\section{RESULTS}

\section{Comparison of Results with Three Naphthols}

Using BPDA together with each of the naphthols (V, VI, and 1-naphthol), followed by exposure to osmium tetroxide, gave results with light micros- 


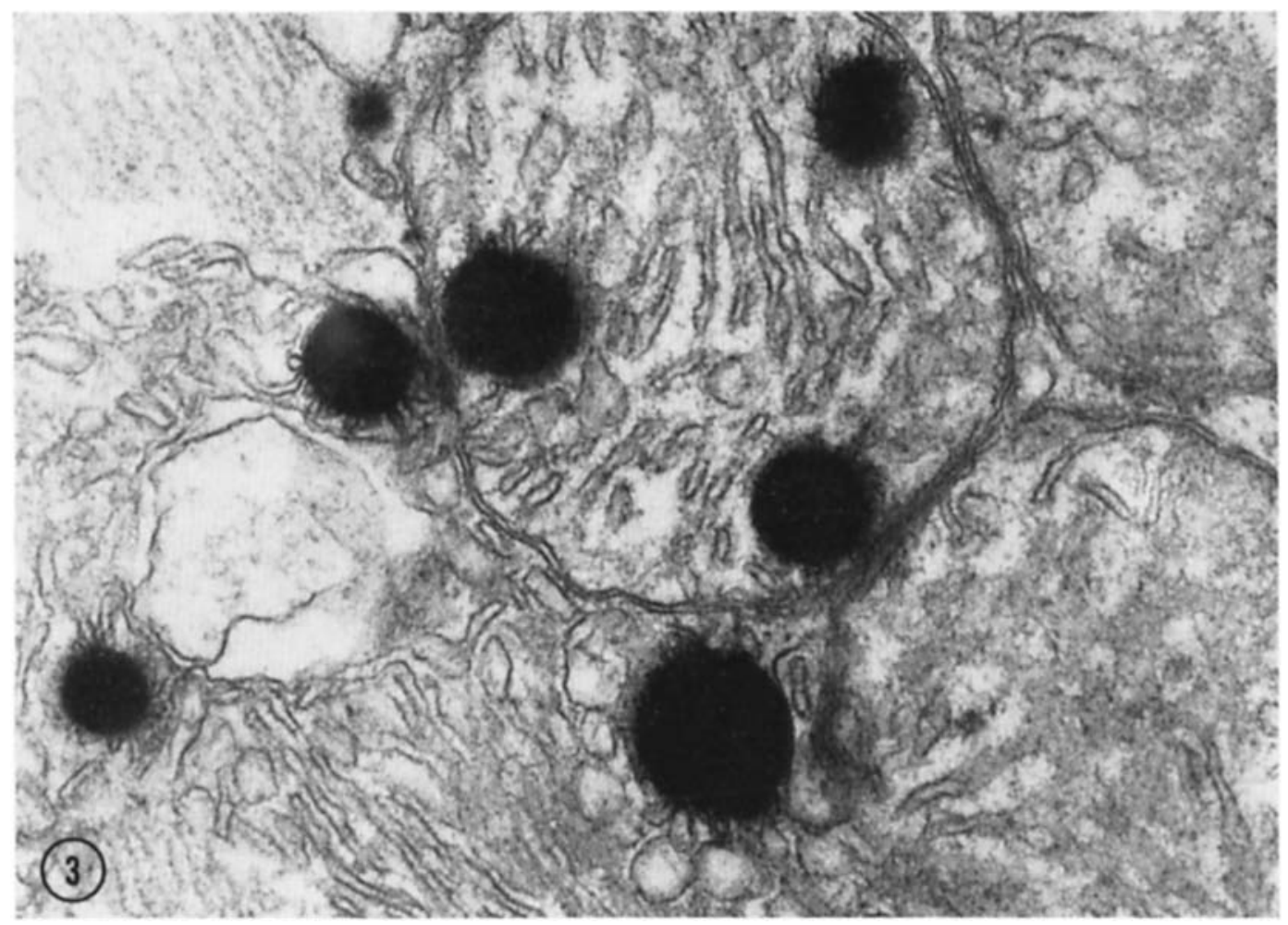

Figure 3 Fresh rat heart. Cytochrome oxidase in opaque droplets; with reagents BPDA and 5-methylthioureido-l-naphthol (V) followed by osmication. Counterstained on a gold grid with the T-O procedure (23). Note location of deposits in close proximity to limiting mitochondrial membranes and involvement of cristae in immediate zone around deposit. The deposits tend to be rounder than with 1-naphthol

(Fig. 2). $\times 55,000$.

copy that were indistinguishable from one another. Although the substituted naphthols V and VI were capable of reacting with osmium tetroxide, thus providing an additional osmiophilic group in the indoaniline pigment, the general distribution and density of the section by light microscopic examination were essentially the same as with 1-naphthol. It was important to compare these naphthols under electron microscopic examination. The general size and distribution of the deposits were similar with the three naphthols, although 1naphthol was more soluble and penetrated a little deeper into the thick sections and blocks of tissue. The use of 1-naphthol eliminated the danger of artifact from special tissue affinity which was present when osmiophilic naphthols V and VI were used. Since the reaction rate of BPDA with naphthol $V$ is less than the reaction rate with naphthol VI or with 1-naphthol, a certain amount of BPDA could react with itself when naphthol $\mathrm{V}$ was used. This side reaction became evident in some of our earlier experiments with naphthols III and $\operatorname{IV}(7,8,20)$ when we noted dark deposits surrounded by a lighter zone of deposit. With 1naphthol, such deposits with two degrees of density were not seen in the electron micrographs, except where a cytochrome oxidase reaction product was in contact with a fat droplet.

\section{Distribution of Reaction Product}

With light microscopy, we again confirmed our earlier impression that the cytochrome oxidase reaction product appeared to be limited to mitochondria in rat heart, much less so with rat kidney, and not at all with rat liver. With electron microscopy, the deposits in heart were noted in mitochondria, especially near their outer and inner limiting membranes (Figs. 2 and 3), and oc- 


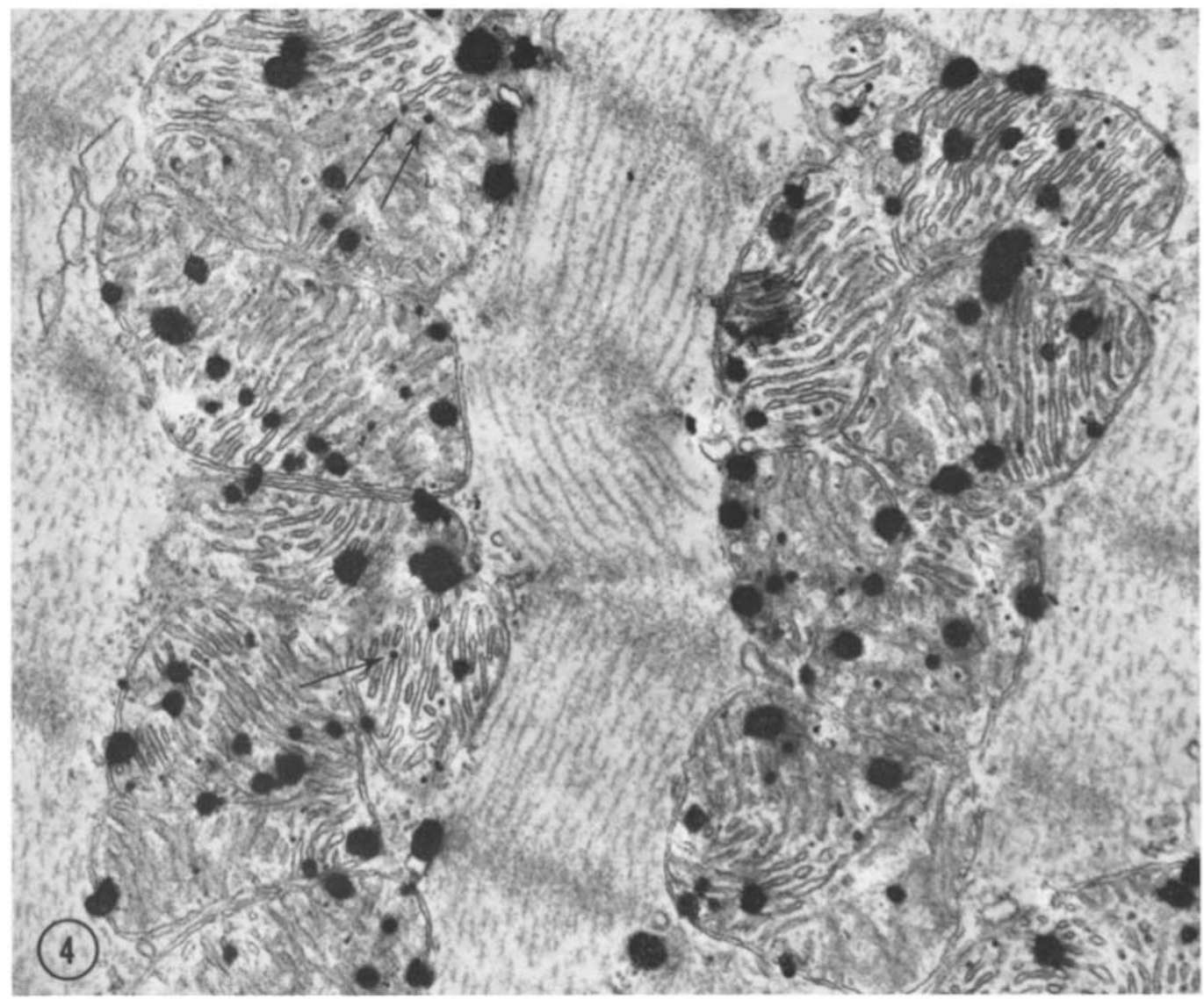

FigURe 4 Rat heart fixed in formaldehyde for $30 \mathrm{~min}$. Small blocks were treated with BPDA and 1-naphthol followed by osmication. Counterstained on gold grids with the T-O procedure (23). Note variation in size and shape of deposits and their location near limiting membranes as well as in deeper portions of the mitochondria. Two droplets in lower portions of figure appear to be located in sarcotubules. The smallest smooth granules are normally occurring mitochondrial dense granules whose contrast is greatly enhanced by the T-O procedure (arrows). $\times 27,000$.

casionally in the sarcotubules (Figs. 4-6, 8, 10). The sarcotubular localization was seen most clearly in the formaldehyde-fixed tissue (Figs. 5, $6,8,10)$. In kidney, the deposits were seen in mitochondria and also in the endoplasmic reticulum and infoldings of the plasma membrane (Figs. 12 and 13). In liver, the deposits were much less frequently seen in relation to the mitochondria, but were most numerous in the endoplasmic reticulum (Fig. 11).

Deposits due to enzymatic activity were most numerous near the cut edge of tissue blocks or of Smith-Farquhar (24) chopped sections. On inspection of the tissue at deeper levels, the deposits became sparser and finally disappeared altogether so that deeper portions of the blocks (beyond 20 $\mu$ ) served as an additional control owing to lack of penetration of reagents. When the $N$-benzyl-pphenylenediamine (BPDA) was used alone, deposits were seen owing to amine reacting with itself (Fig. 6). When osmiophilic naphthols $\mathrm{V}$ and VI were used alone, no deposits were seen, but some increased thickness of the cristae of many mitochondria was noted, owing to uniform staining of the intracristal space (Fig. 7). This was not observed with l-naphthol used alone. In the presence of $0.01 \mathrm{M}$ potassium cyanide, all cytochrome oxidase activity was inhibited and no 


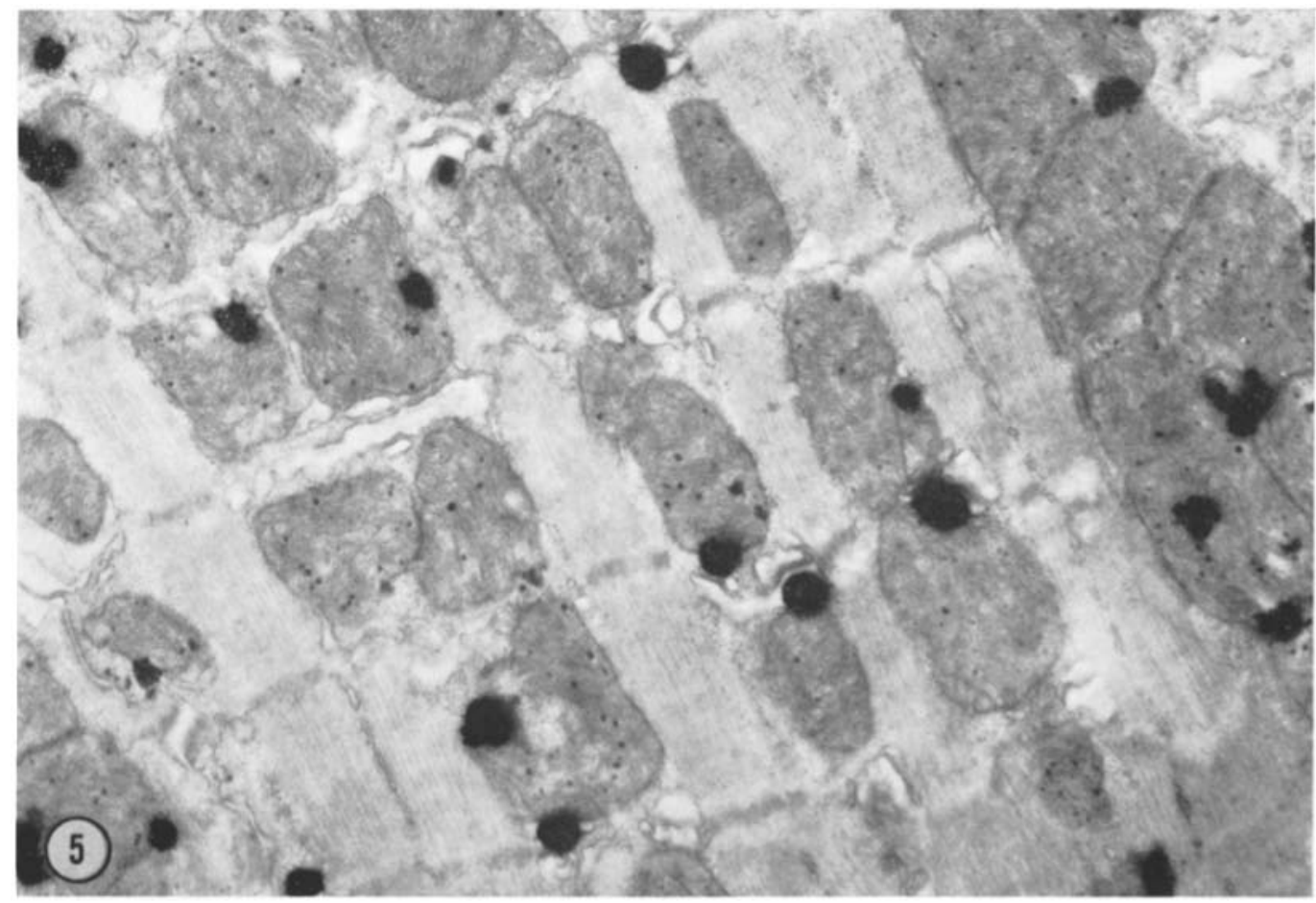

FIGURE 5 Rat heart fixed as in Fig. 4 and treated with BPDA and 5 -methyl-thioureido-I-naphthol (V) followed by osmication. Counterstained with the T-O procedure. Note that one or two droplets are in sarcotubules, whereas most are in mitochondria. Some deposits are mulberry-shaped. The contrast of small dense granules normally occurring in mitochondria is enhanced by the T- $O$ procedure. $\times 19,000$.

deposits were seen in heart, kidney, or liver, either in or outside of the mitochondria.

Because the T-O procedure enhanced the contrast of lipid droplets and the dense granules of mitochondria, care was taken to note their distribution in parallel sections not exposed to the T-O procedure. They could also be recognized by their distribution in deeper positions of the tissue blocks and thick sections in which histochemical reagents had failed to penetrate, whereas deposits due to cytochrome oxidase activity were confined to regions near the cut edges. The latter deposits were generally smaller than lipid droplets and larger than the dense granules, with $20-\mathrm{min}$ incubations (Figs. 9, 11-13). Longer incubation gave more numerous deposits, and owing to coalescence, larger deposits were formed with mulberry shape. Shorter incubations gave fewer and smaller deposits which were more difficult to find and identify with certainty. The longer the period of formaldehyde fixation, the fewer the deposits. In mitochondria containing many deposits, there was no increase in contrast of the cristae as compared to that of controls or neighboring unreactive mitochondria (Figs. 4, 10). This was confirmed in sections not treated with the $\mathrm{T}-\mathrm{O}$ procedure. In mitochondria near the periphery of sections, deposits were numerous in all parts of the mitochondrion (Fig. 4), whereas in deeper areas, in which reaction deposits were sparser, the deposits were usually found to be located at the outer limiting membrane (Figs. 8, 10). The deposits themselves were round and, where coalescence occurred, they were mulberry-shaped (Figs. 2, 5, $11,12)$. They were always much denser than lipid droplets in sections not treated with the $\mathrm{T}-\mathrm{O}$ procedure, but only slightly more dense after the T-O procedure, which increases contrast of osmiophilic lipid to approach that of the opaque deposits (Fig. 11) resulting from the histochemical reaction. 

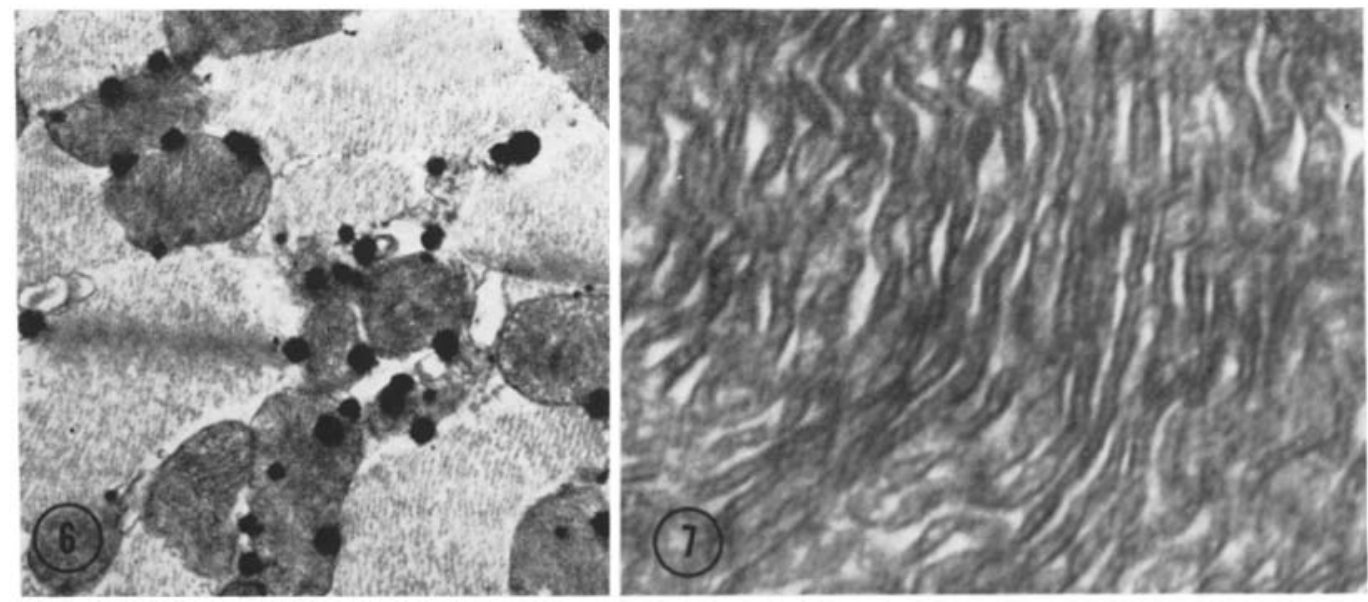

Figure 6 Rat heart fixed in formaldehyde for $1 \mathrm{hr}$ and cut into $30 \mu$ sections with a Smith-Farquhar chopper (24). The sections were treated only with BPDA and no naphthol, followed by osmication. Two molecules of BPDA were oxidized by cytochrome oxidase to an indamine which was osmiophilic. Counterstained with the T-O procedure. Note droplets of reaction product in contact with mitochondrial membranes and in some sarcotubules. $\times 16,000$.

Figure $\gamma$ Fresh rat heart treated only with the osmiophilic naphthol, 5-methyl-thioureido-1-naphthol (V) and no BPDA, followed by osmication. Counterstained with the T-O procedure. No pigment due to cytochrome oxidase activity was produced, but in some of the mitochondria the osmiophilic naphthol apparently stained mitochondrial cristae, with some staining of intracristal spaces and narrowing of intercristal spaces. $\times 95,000$.

\section{DISCUSSION}

The observation with light microscopy that the localization of cytochrome oxidase, as shown by the Nadi reaction, appears to be confined to mitochondria in rat heart, to be less confined to mitochondria in rat kidney, and even less frequently confined to mitochondria in rat liver is substantiated by the present study of these tissues with the electron microscope. (Figs. 4, 11, 12). The histochemical method used here is based upon the Nadi reaction, but involves conversion of the final organic pigment, an indoaniline produced by the oxidation of 1-naphthol and $N$-benzyl- $p$ phenylenediamine, to a coordination polymer (6), osmium black, with osmium tetroxide. We included catalase in the medium to destroy all traces of hydrogen peroxide so that peroxidase would not be demonstrated, and we also added cytochrome $c$ to insure its presence in excess so that the histochemical reaction would be cytochrome-oxidase dependent. This was more important for fixed tissue than for fresh tissue, and for thin sections than for blocks of tissue. The possibility exists that the protein adjuvants, catalase and cytochrome $c$, were not able to penetrate tissue blocks and thick sections to the same extent, if at all, as the Nadi reagents. This problem is not encountered with thin frozen sections in light microscopy. However, it is also worth noting that endogenous cytochrome $c$ would be less likely to diffuse out of tissue blocks than from thin frozen sections. Furthermore, since cytochrome oxidase oxidizes cytochrome $c$ in the presence of oxygen, which then in turn, oxidizes the Nacii reagents, the possibility exists that the oxidized form of cytochrome $c$ could have diffused a distance amounting to fractions of a micron from the site of its oxidation before it was able to oxidize the Nadi reagents. This could explain the formation of a droplet-like deposit. However, if this was the explanation for finding deposits outside the mitochondria in liver and kidney, we should have expected to obtain the same artifact to the same extent in heart muscle. In some instances, deposits due to enzymatic activity were seen in the sarcotubules of rat heart (Figs. 5, 8, 10), but the greatest concentration of deposits was located within the mitochondria (Fig. 4). Complete in- 

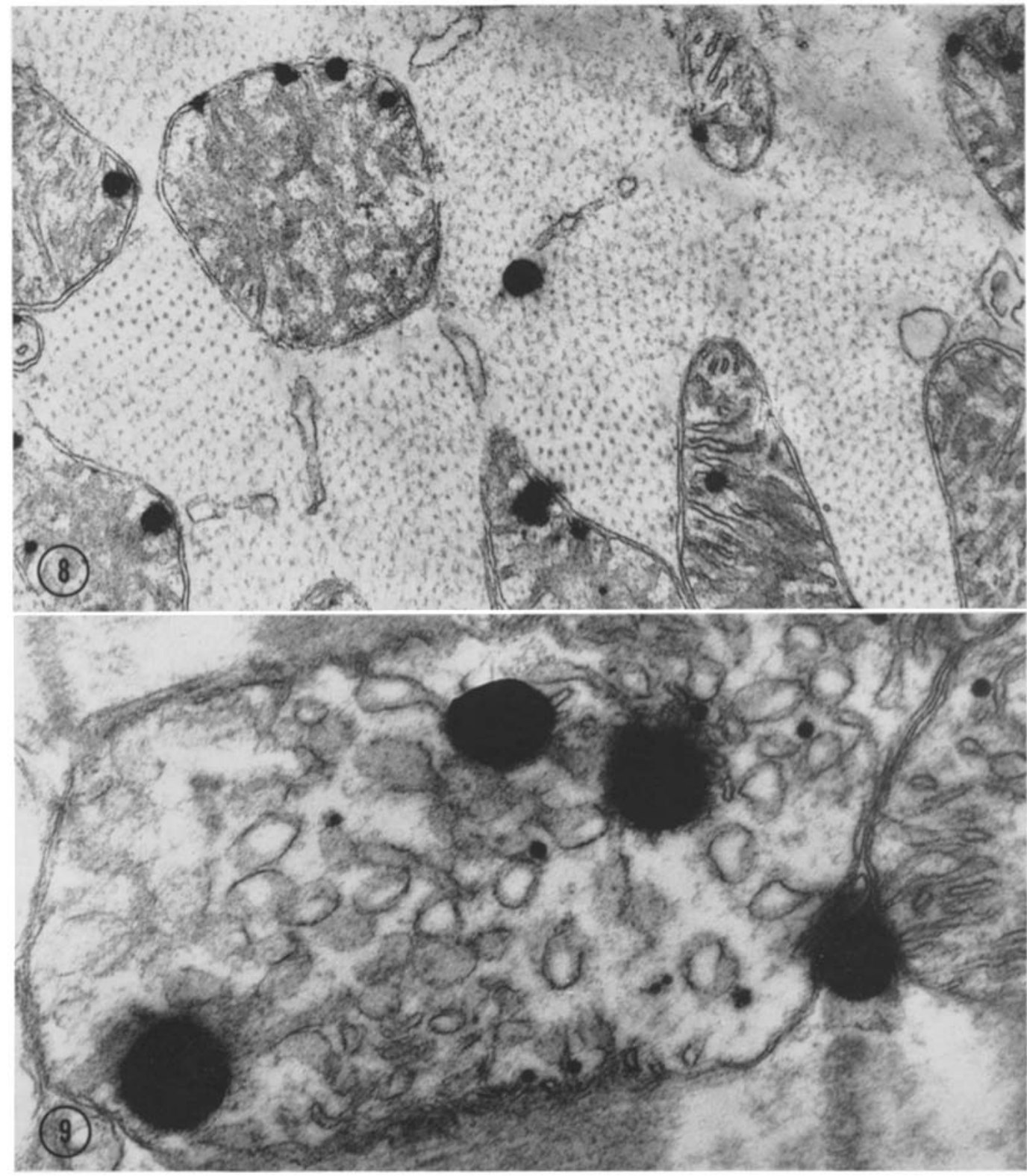

FIGURE 8 Rat heart fixed in formaldehyde for $30 \mathrm{~min}$, and small blocks were treated with BPDA and 1-naphthol followed by osmication. Counterstained with the T-O procedure. Note deposits close to inner limiting mitochondrial membranes and one deposit in a sarcotubule (center) $\times 27,000$.

Figure 9 Rat heart fixed and treated as in Fig. 8 except for the use of osmiophilic naphthol $V$ instead of 1-naphthol. Distribution of deposits in mitochondria are similar. Cristae are not unusually stained. $\times 55,000$. 


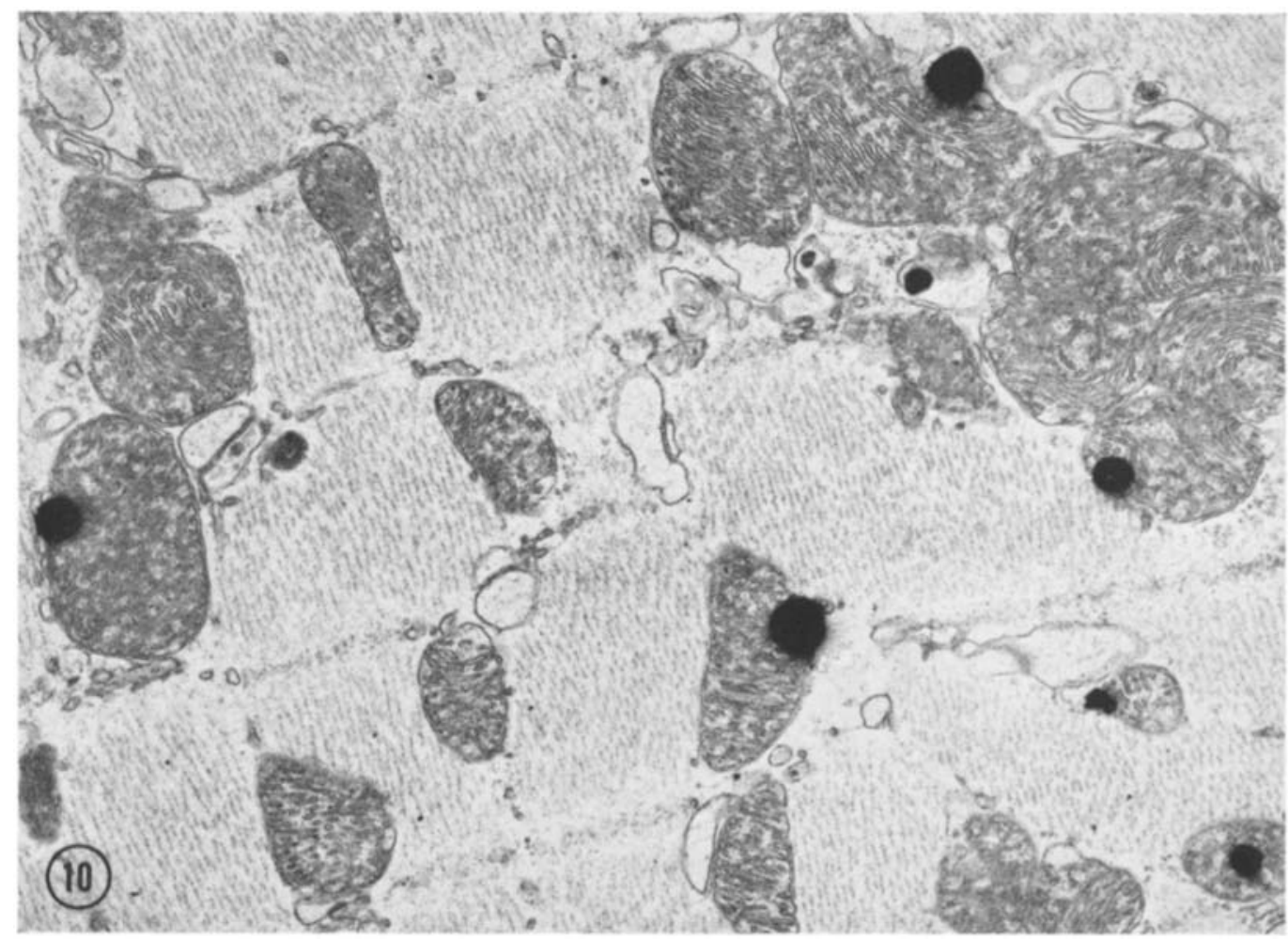

Frgure 10 Rat heart fixed in formaldehyde for $1 \mathrm{hr}$ and cut into $30-\mu$ sections with a Smith-Farquhar chopper (24). Treated with BPDA and 1-naphthol, followed by osmication. Counterstained with the T-O procedure. Note excellent preservation and stain of mitochondrial and sarcotubular membranes. Deposits are similar in location to those noted when the histochemical reaction was carried out on blocks of fresh or fixed tissue. $\times 19,000$.

hibition of cytochrome oxidase with potassium cyanide suggests that the Nadi reagents are not oxidized by any other electron-transport system in liver and kidney even though they were found outside the mitochondria. No significant differences in this general localization of cytochrome oxidase activity was noted in the electron microscope when other diamines or the naphthols other than 1-naphthol were used (Figs. 3, 5). The electron micrograph of cytochrome oxidase in rat heart published by Sabatini et al. (19) shows a similar, though stellate-shaped distribution of the deposits produced after fixation in hydroxyadipaldehyde with the reagents recommended by Burstone (3), p-aminodiphenylamine and 3amino-9-ethylcarbazole or $p$-methoxy-p-aminodiphenylamine. The electron opacity of these deposits indicates that osmium black was produced after exposure of the indamine analogues to osmium tetroxide, although the authors attributed the deposits to the contrast provided by the organic pigment (19). There is also the suspicion from their photograph that the organic pigment was crystalline prior to exposure to osmium tetroxide.

In most instances, the electron-opaque deposits produced by the Nadi reaction were round or mulberry-shaped and varied in size depending upon the duration of the incubation or the gradient in concentrations of the reagents from the surface of the tissue block to its interior (Fig. 4). The deposits did not delineate underlying membranous structures, and their large droplet character on long incubation may have been due to supersaturation of the medium with the indoaniline and deposition on nearby droplets rather than initiation of new foci of deposition. This shortcoming is inherent in the Nadi reaction for cytochrome oxidase, and further improvement in ultrastruc- 


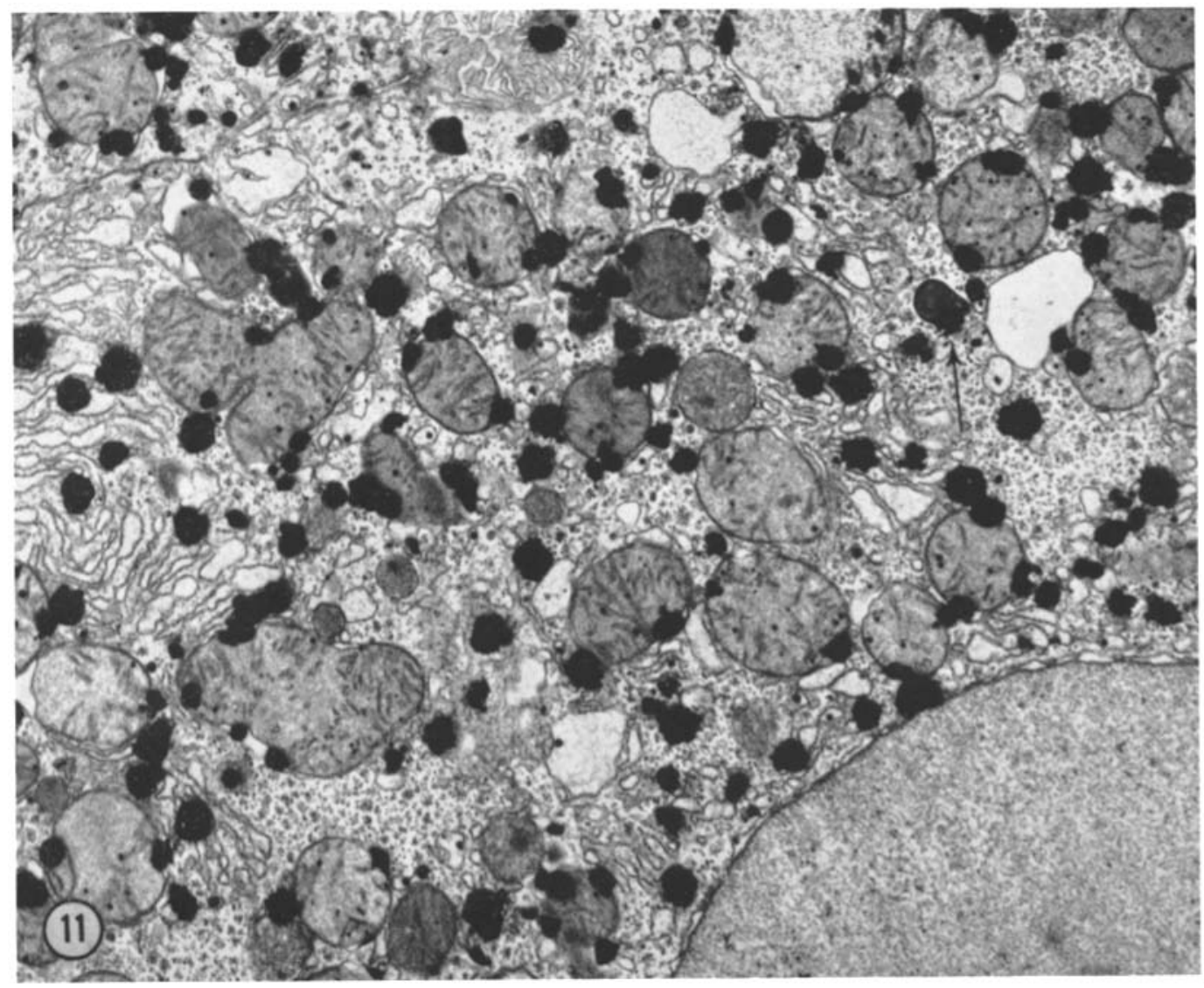

FIgURE 11 Rat liver fixed in formaldehyde for $30 \mathrm{~min}$ and treated with BPDA and 1-naphthol, followed by osmication. Counterstained with the T-O procedure. Note deposits due to cytochrome oxidase activity on mitochondrial limiting membranes, and in even greater abundance in endoplasmic reticulum unrelated to mitochondria. One droplet is in contact with the nuclear envelope in lower right. Note one deposit in contact with less opaque lysosome or autophagosome (arrow). $\times 14,000$.

tural demonstration for electron microscopy must await design of new reactions for its demonstration.

There were no significant differences in the nature of the deposits when fresh tissues were compared to the formaldehyde-fixed or frozen sections. There were great differences in the preservation of ultrastructure, however. Frozen sections gave the poorest results, fresh tissues were better, and formaldehyde-fixed tissue yielded the best preservation of ultrastructure and made possible the use of the Smith-Farquhar chopper (24). When sections were chopped $30 \mu$ in thickness, reagents penetrated the full thickness of the sections from both surfaces, but orienting the Araldite-embedded sections and cutting ultrathin sections required greater technical care than when blocks of tissue were used. Fixation resulted in the sacrifice of some enzymatic activity, a loss which was greater after $1 \mathrm{hr}$ of fixation than after $30 \mathrm{~min}$.

Worth noting is the striking difference between the deposits produced by cytochrome oxidase and those produced by succinic dehydrogenase and $\mathrm{NADH}_{2}$-diaphorase with recently developed methods for their ultrastructural chemical demonstration (21). Each of these dehydrogenases produced osmium-containing deposits on the cristae of certain mitochondria of rat heart, in a continuous membranous deposit that in heavily stained preparations extended into the intracristal spaces rather than into the intercristal spaces. These methods enhanced the contrast and delineated 


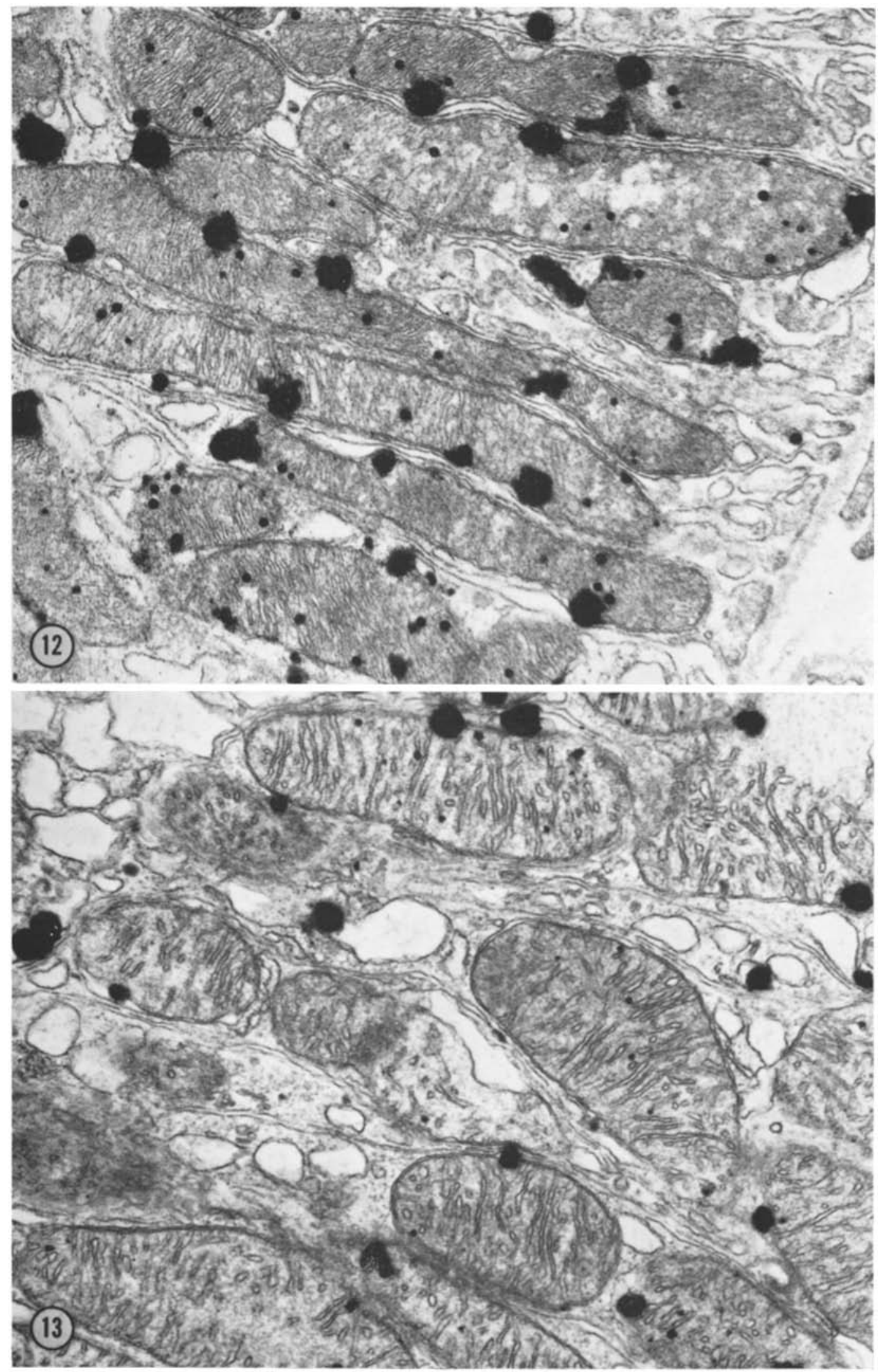

Frgures 12 and 13 Rat kidney fixed in formaldehyde for 30 min and treated with BPDA and 1-naphthol, followed by osmication. Counterstained with the T-O procedure. Note normally occurring mitochondrial dense granules and large deposits due to cytochrome oxidase on, or close to mitochondrial limiting membranes and some deposits in relation to infoldings of the plasma membranes. $\times 27,000$. 
the underlying membranous structure. The outer limiting membrane of the mitochondrion was not stained by the dehydrogenases (21), whereas the round deposits due to cytochrome oxidase activity were often in contact with either outer or inner limiting membranes of the mitochondria of rat heart (Figs. 2, 3, 5, 8-10) as well as rat liver and kidney (Figs. 11-13). The use of naphthols other than 1-naphthol, that were expected to give pigments with less lipid solubility prior to exposure to osmium tetroxide, such as naphthols $\mathrm{V}$ and VI, did not alter the general droplet-like character of the cytochrome deposits in electron microscope preparations (Figs. 3,5). We have no explanation at the present time for the difference in character and localization of the ultrastructural chemical reaction product with cytochrome oxidase as compared to that with the dehydrogenase, other than the substantivity of the diformazans as compared to that of the indoanilines. As pointed out earlier (7), the limitations inherent in methods based upon production of organic pigments are

\section{REFERENCES}

1. Billman, J. H., and J. Diesing. 1957. J. Org. Chem. 22:1068.

2. Burstone, M. S. 1959. J. Histochem. Cytochem. $7: 112$.

3. Burstone, M. S. 1960. J. Histochem. Cytochem. $8: 63$.

4. Freeman, J. H., and B. O. Spurlogk. 1962. $J$. Cell Biol. 13: 437.

5. Hanker, J. S., G. Deb, H. L. Wasserkrug, and A. M. Seligman. 1966. Science. 152:1631.

6. Hanker, J. S., F. Kasler, M. G. Bloom, J. S. Copeland, and A. M. Seligman. 1967. Science. 156:1737.

7. Hanker, J. S., A. R. Seaman, L. P. Weiss, H. Ueno, R. A. Bergman, and A. M. SeligMaN. 1964. Science. 146:1039.

8. Hanker, J. S., A. R. Seaman, L. P. Weiss, H. Ueno, H. Dmoghowski, L. Katzoff, and A. M. Seligman. 1965. J. Histochem. Cylochem. $13: 3$.

9. Karnovsky, M. J. 1961. J. Cell. Biol. 11:729.

10. KuRtz, S. M. 1961. J. Ultrastruct. Res, 5:468.

11. Lantz, R., and P. Obellianne. Bull Soc. Chim. France 311 (1956); Fr. Patent 1,094,452 (1955); Chem Abstr. 53:1248 (1959).

12. Meldola, R., and E. H. R. Salmon. 1888. J. Chem. Soc. 53:779.

13. Meldola, R., and J. H. Coste. 1889. J. Chem. Soc. 55:591. not eliminated by their conversion to osmium black in a later step of the procedure.

Very recent work in collaboration with Dr. Morris J. Karnovsky indicates that cytochrome oxidase is able to oxidize $3,3^{\prime}$-diaminobenzidine to an osmiophilic, apparently polymeric material which results in deposits that are non-droplet in character. Comparison of results with this newer method will be published later.

Acknowledgement is due Dr. Arlene R. Seaman and Miss Harriet K. Storm for assistance in the early phase of the work which was done before the development of the new reagents, BPDA and naphthols $\mathrm{V}$ and VI, and before development of the OTO method; to Mr. Stuart Linus for assistance in organic synthesis; and to Mr. Michael Friedman for photographic assistance.

This investigation was supported by a research grant (CA-02478) from the National Cancer Institute, United States Public Health Service, Bethesda, Maryland.

Received for publication 23 February 1967.

14. Naghlas, M. M., D. T. Grawford, T. P. Goldstein, and A. M. Seligman. 1959. J. Histochem. Cytochem. 6:445.

15. Pease, D. C. 1964. Histological Techniques for Electron Microscopy. Academic Press Inc., New York. 2nd edition.

16. Plapinger, R. E., G. Deb, S. J. Linus, L. KATZOFf, and A. M. Seligman. 1967. J. Histochem. Cytochem. In press.

17. Reynolds, E. S. 1963. J. Cell Biol. 17:208.

18. Righardson, K. C., L. Jarett, and E. H. Finke. 1960. Stain Technol. 35:313.

19. SABAtint, D. C., K. BensGh, and R. J. BarRNETT. 1963. J. Cell Biol. 17:19.

20. Seligman, A. M. 1964. Proceedings of the Second International Congress for Histo- and Cytochemistry. Springer-Verlag, Berlin. 9.

21. Seligman, A. M., H. Ueno, Y. Morizono, H. L. Wasserkrug, L. Katzoff, and J. S. Hanker. 1967. J. Histochem. Cytochem. 15:1.

22. Seligman, A. M., H. Ueno, H. L. Wasserkrug, and J. S. Hanker. 1966. Ann. Histochim. 11:115.

23. Seligman, A. M., H. L. Wasserkrug, and J. S. Hanker. 1966. J. Cell Biol. 30:424.

24. SMITH, R. E., and M. G. FARQUHAR. 1965. Sci. Inst. News. 10:13. 